\title{
Individualized male dress shirt adjustments using a novel method for measuring shoulder shape
}

\author{
KyoungOk Kim ( Institute for Fiber Engineering (IFES), Interdisciplinary Cluster for Cutting Edge Research \\ (ICCER), Shinshu University Ueda Japan ), \\ Noriaki Innami ( Shinshu University Ueda Japan ) ( Japan ), \\ Masayuki Takatera ( Institute for Fiber Engineering (IFES), Interdisciplinary Cluster for Cutting Edge \\ Research (ICCER), Shinshu University Ueda Japan ), \\ Tadaharu Narita ( Flex Japan Co.,LTD Chikuma Japan ) \\ Midori Kanazawa ( Flex Japan Co.,LTD Chikuma Japan ) \\ Yuji Kitazawa ( Flex Japan Co.,LTD Chikuma Japan )
}

\begin{abstract}
takatera@shinshu-u.ac.jp

Purpose: This paper investigated the current challenges to making individualized men's dress shirt adjustments, and devised a novel measurement method to assess shoulder shape.
\end{abstract}

Design/methodology/approach: To understand the common complaints about ready-to-wear dress shirts, a wear evaluation with 15 Japanese males was performed. The shoulder components of these shirts could not be adjusted using any currently available measurement methods. The three-dimensional body shape of two subjects who had a problem with the shoulder of ready-to-wear shirts was compared with a dummy designed to represent the average Japanese male.

Findings: We determined that one of the subjects with an incompatible shoulder fit had a shoulder point line that was anterior to the one measured on the average dummy. The other subject had a smaller shoulder angle than the average dummy. To effectively measure the wearer's shoulder characteristics, we devised a new measuring device that can measure the shoulder angle and its degree of forward thrust. With this device, it was possible to understand the wearers' shoulder types and make appropriate dress shirt adjustments.

Originality/value: We devised a new measuring device to assess shoulder angle and forward thrust, qualities that previously could not be measured without three-dimensional analysis. Using this device it was possible to understand the wearers' shoulder types and make appropriate dress shirt adjustments.

\section{Introduction}

Dress shirts are pieces of clothing for the upper part of the body with sleeves and a collar, usually worn by men. In the same way as other ready-to-wear male clothing, various shirt sizes are produced. When making a ready-to-wear shirt, a pattern is made to fit a standard-sized body, which is called a master pattern. By expanding or contracting the master pattern according to the size pitch, various shirt sizes are made. This system is called grading (Cooklin, 2000).

However, ready-to-wear shirts based on graded patterns can often be uncomfortable when not fitted according to the wearer's individual body shape (Coffin, 1998). In the Japanese apparel size system (Japanese Standards Association, 2015), the shirt size is based upon the wearer's neck circumference and the distance measured from the back of the neck to the wrist through the shoulder (sleeve length) in addition to body type sizing based upon the diameter of the chest and waist. During the grading process, the typical dimensions of the chest, neck and sleeve length are used. Other measurements are assumed based upon these initial values. Even if the neck and sleeve measurements were individually fitted, they are insufficient to ensure the wearing comfort of various body types. To make a more comfortable shirt, it is necessary to understand the wearer's body shape and make more specific measurements.

To improve the wearer's satisfaction and comfort, a good alternative to stock sizing is a custom-made clothing service (Ives et al., 2003). For custom-made shirts, more specific dimensions are necessary to detail the wearer's individual body characteristics. The relationships between the clothing pattern and the wearer's body measurements were investigated by several prior studies. Makabe and Beppu (1997) and Beppu and Makabe (1998) investigated the relationship between the body measurements of Japanese females and the geometric qualities of the basic patterns that were made to fit the individuals. Chin-Man Chen (2007) evaluated 
the fit of the basic garments made for Taiwanese female students with various body characteristics. In their study, many measurements were necessary to make a well fitted garment. For shirts, A. P. Chan et al. (2003 and 2005) showed that the pattern drafting methods for shirts must be improved, and proposed a prediction method for establishing pattern parameters using three-dimensional body measurements. They went on to propose shirt patterns for different body sizes using multiple linear regression analyses (Chan et al. 2005). Although they proposed a prediction method for pattern parameters, it requires extensive measurements using a threedimensional scanner that is expensive and not easily adaptable for mass customization. A simpler method is necessary for shirt customization, with particular emphasis on Internet availability. When making a fitted shirt, adjusting a ready-made shirt is more effective than making many custom measurements, as there is an adequate selection of ready-made shirts for most types of neck sizes and sleeve lengths. However, current measurement methods are inaccurate, particularly when assessing the shoulder.

Until now, a shirt's adequacy of fit can only be confirmed by wearing the actual shirt. Appearance is not enough to ensure comfortability. Although a proficient pattern-maker observes and measures the wearer's body, it is still difficult to predict necessary pattern adjustments without fitting. Shoulder comfort is a big problem for shirt makers because of the wide range of different shoulder shapes (Coffin, 1998). The characteristic shoulder shapes are largely defined as either square or sloping, depending on the angle of the shoulder. Shoulders are also classified into forward or backward thrusting shapes based upon the anteriorposterior direction of the shoulder line.

In this study we investigated aspects of ready-to-wear shirts that are unsatisfactory by performing wear experiments on Japanese males. Our aims were to confirm the importance of the customization of the shoulder elements of shirts. We also investigated the characteristics of the shoulder forward thrust and square shapes by measuring three-dimensional body shapes. Herein we propose a simple measurement method for shoulder shape by adjusting the basic shirt pattern used for the customization, in consideration of the wide range of differences in shoulder shape.

\section{Experimental}

\section{Dissatisfied points of ready-to wear shirt}

To clarify the problem of ready-to-wear dress shirts, we investigated the most dissatisfying aspects of these shirts by performing wear evaluation tests. Seventeen Japanese male subjects from 20-50 years old with various body shapes volunteered to participate in this test.

Based upon the subjects' neck circumferences and sleeve lengths, two expert pattern makers selected a ready-to-wear shirt. Table 1 shows the measurements of the subjects and their selected shirt sizes. Suitable sizes of ready-to-wear shirt were not found for subject 11 and 16. Thus, both subjects were excluded. Subjects wore a $100 \%$ cotton undershirt and trousers with a rubber waist band along with the shirt. The shirt hem was tucked into the trousers in a way that the subject most typically wears it. Figure 1 shows an example of the shirt and its design pattern. The subjects were permitted to move freely and watched their appearance using a mirror. We also took pictures of them from the front, side and back.

A survey was then administered related to their comfort and appearance during the fitting. We asked subjects about their perception of the shirt based on the following characteristics; 1) size, 2) comfort, 3) appearance, 4) ease of neck fit, shoulder, sleeve length and girth and 5) overall entire satisfaction on a 10-point scale. Investigators then correlated survey results with the pictures taken during the fit.

For those subjects who were dissatisfied with the ready-to-wear shirts, the experts adjusted their shirt pattern and re-assessed their satisfaction. 

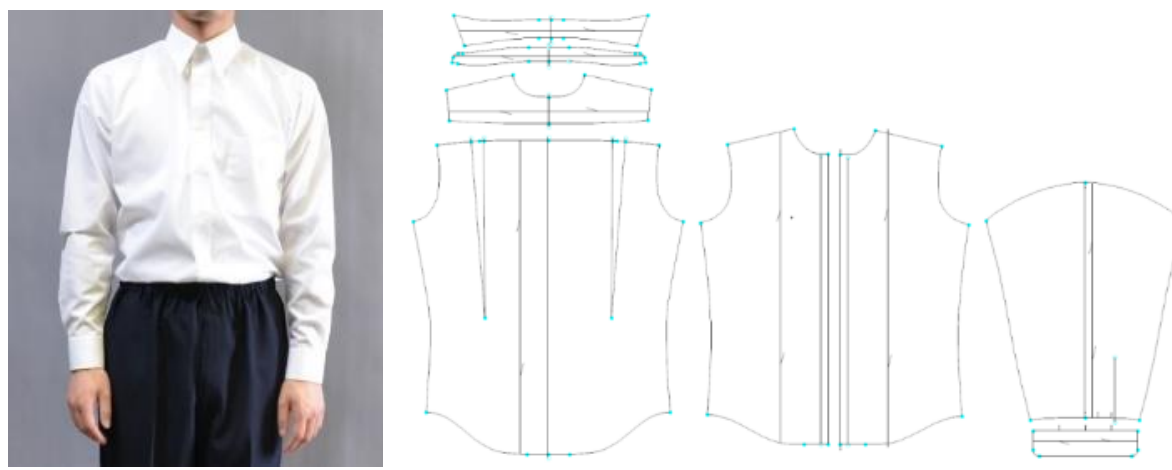

Figure 1 A standard shirt for the standard body and its deign pattern

Table 1 subject measurements, assigned shirt sizes

\begin{tabular}{|c|c|c|c|c|}
\hline \multirow{2}{*}{ Subject No. } & \multicolumn{2}{|c|}{ Subject measurement } & \multicolumn{2}{c|}{ Assigned shirt size } \\
\cline { 2 - 5 } & Neck $(\mathrm{cm})$ & Sleeve length $(\mathrm{cm})$ & Neck $(\mathrm{cm})$ & Sleeve length $(\mathrm{cm})$ \\
\hline 1 & 33 & 74 & 36 & 74 \\
\hline 2 & 34 & 85 & 37 & 84 \\
\hline 3 & 36 & 82 & 38 & 82 \\
\hline 4 & 38 & 81 & 40 & 80 \\
\hline 5 & 33 & 78 & 36 & 78 \\
\hline 6 & 35 & 83.5 & 37 & 84 \\
\hline 7 & 36 & 83 & 38 & 82 \\
\hline 8 & 34 & 79 & 37 & 80 \\
\hline 9 & 34 & 84 & 37 & 84 \\
\hline 10 & 40 & 78 & 42 & 78 \\
\hline 11 & 37 & 93 & - & - \\
\hline 12 & 41 & 84 & 43 & 84 \\
\hline 13 & 39 & 82 & 41 & 84 \\
\hline 14 & 40 & 84 & 42 & 86 \\
\hline 15 & 43 & 87 & 45 & 84 \\
\hline 16 & 44 & 87 & - & - \\
\hline 17 & 41 & 84 & 43 & \\
\hline
\end{tabular}

*Sleeve length measurement: the distance from the back of the neck to the wrist through the shoulder

\section{Results and discussion}

\section{Dissatisfied point of ready-to-wear shirt}

Table 2 shows the results of the questionnare administered following the wearing tests. The overal subject satisfaction rate was $66 \%$. The main reasons for subject dissatisfaction (characterized by dissatisfaction rates > $40 \%$ ) were a tight neck, an incompatible sleeve width and length and shoulder width. Figures 2-4 show pictures of subjects who were either satisfied or dissatisfied with their neck, sleeve or shoulder dimensions. A loose fit around the trunk was also a common reason for dissatisfaction. Although this quality is not directly related to wear comfort, it was found to affect the wearer's overall satisfaction with the shirt. 
Table 2 Satisfaction score and reason of dissatisfaction

\begin{tabular}{|c|c|c|c|c|c|c|c|}
\hline \multirow[b]{2}{*}{ Subject No. } & \multirow[b]{2}{*}{$\begin{array}{c}\text { Satisfaction } \\
\text { score }\end{array}$} & \multicolumn{6}{|c|}{ Sources of dissatisfaction } \\
\hline & & $\begin{array}{l}\text { 1) Neck } \\
\text { diameter }\end{array}$ & $\begin{array}{l}\text { 2) Sleeve } \\
\text { length }\end{array}$ & 3) Sleeve width & $\begin{array}{l}\text { 4) Shoulder } \\
\text { width }\end{array}$ & $\begin{array}{l}\text { 5) Arm } \\
\text { hole }\end{array}$ & $\begin{array}{l}\text { 6) Feeling } \\
\text { around trunk }\end{array}$ \\
\hline 1 & 8 & & & wide & & & \\
\hline 2 & 8 & & & & & & large \\
\hline 3 & 7 & tight & short & wide & tight & & \\
\hline 4 & 6 & & & wide & & large & large \\
\hline 5 & 7 & tight & & & & & small \\
\hline 6 & 4 & tight & & & tight & tight & \\
\hline 7 & 6 & tight & & tight (upper arm) & & & \\
\hline 8 & 7 & & & wide & & & \\
\hline 9 & 6 & tight & long & wide & & & \\
\hline 10 & 7 & & long & & wide & & large \\
\hline 12 & 4 & tight & short & & tight & tight & \\
\hline 13 & 7 & & & & & & \\
\hline 14 & 6.5 & & & tight (cuffs) & & & large \\
\hline 15 & 8 & tight & & & wide & & large \\
\hline 17 & 7.5 & tight & long & tight (upper arm) & tight & small & \\
\hline $\begin{array}{c}\text { Percentage } \\
\text { dissatisfied (\%) }\end{array}$ & 34.0 & 53.3 & 33.3 & 53.3 & 40.0 & 26.7 & 40.0 \\
\hline
\end{tabular}

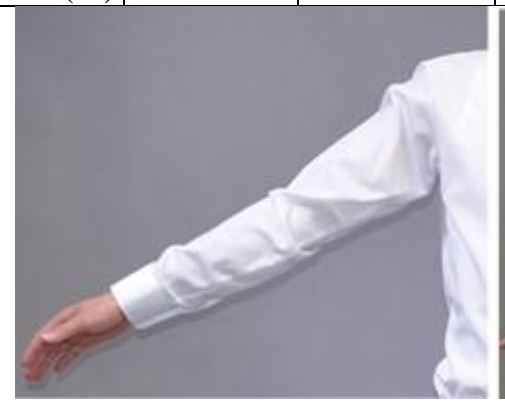

(a)

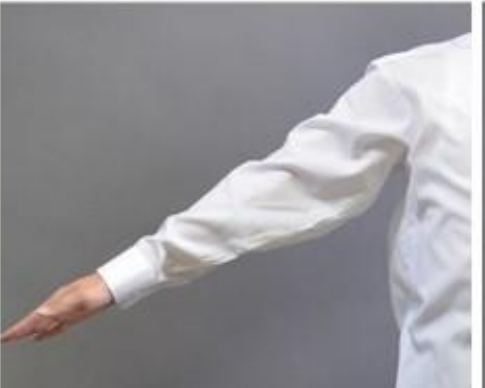

(b)

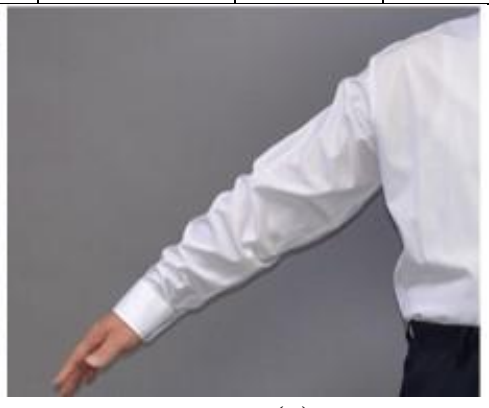

(c)

Figure 2 The perception of sleeve length by subjects 6,1 and 17; (a) subject 6 : satisfied, (b) subject 1: dissatisfied (wide) and (c) subject 17: dissatisfied (tight on upper arm)

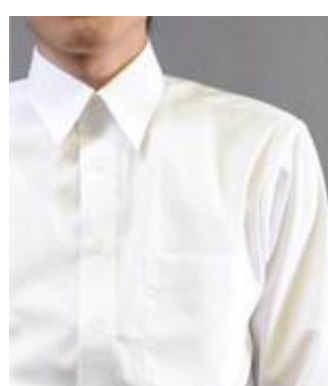

(a)

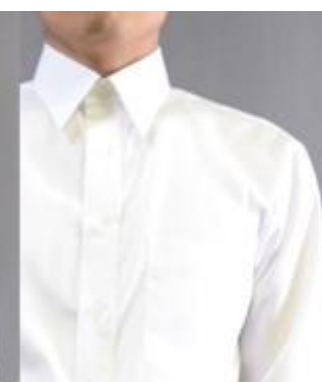

(b)

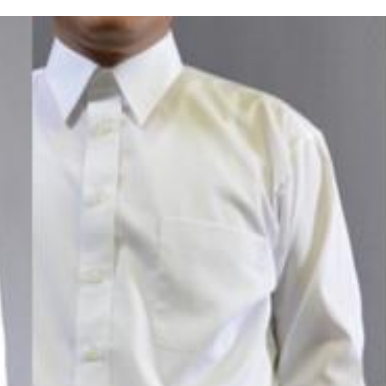

(c)

Figure 3 The perception of shoulder width by subjects 2, 6 and 10; (a) subject 2: satisfied, (b) subject 6 : dissatisfied (narrow) and (c) subject 10: dissatisfied (wide) 


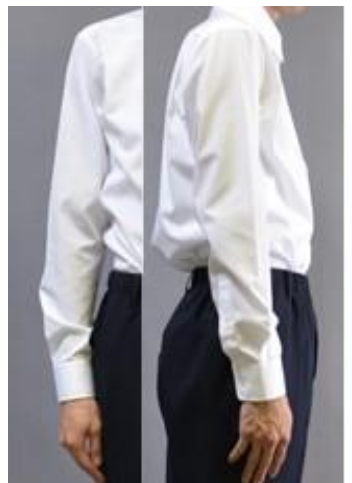

(a)

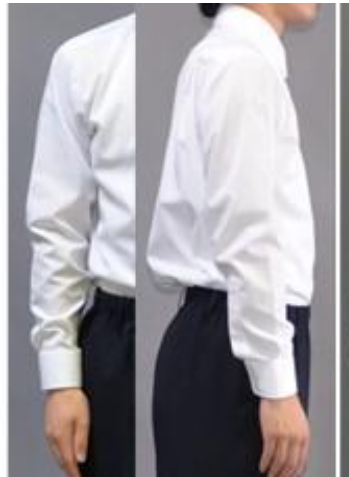

(b)

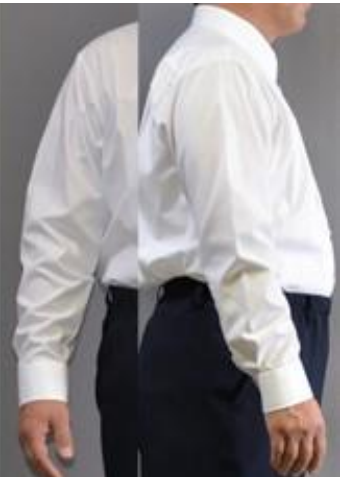

(c)

Figure 4 The perception of sleeve length by subjects 2,3 and 17; (a) subject 2: satisfied, (b) subject 3: dissatisfied (short) and (c) subject 17: dissatisfied (long)

The subjects' disaffection with the neck diameter of the shirt was eliminated by wearing a shirt with a neck size that was one size larger. Disaffection with their sleeve length was also eliminated by wearing a shirt that was one size longer. However, subjects 3 and 6 were not satisfied with their adjusted sizes. The experts were not able to adjust these subjects' shirts based upon their questionnaire results and pictures. After checking the subjects' wear and hearing their comments, the experts adjusted the shirt pattern and made appropriate modifications.

The shoulder type of subjects 3 and 6 are shown in Table 3 . The experts labeled subject 3 as a forward thrusting shoulder and subject 6 as a square shoulder. Pictures of subjects 3 and 6 and their adjusted shirt patterns are shown in Figures 5 and 6. Using the modified shirts, the wear evaluation was repeated with the same questionnaire. The satisfaction scores of these subjects and a description of their pattern adjustment method are shown in Table 3. Both subjects rated their satisfaction with the modified shirts as at least 8 of 10, which was higher than the average score from the ready-to-wear shirts. In addition, their previously identified areas of dissatisfaction with the shirt were resolved. It was found that the pattern adjustment methods used by the experts were reasonable. However, they couldn't make these adjustments based upon conventional measurements such as sleeve length, shoulder width and neck circumference. Therefore, it was determined that a new measurement method was necessary to adjust the shirt pattern for wearers with a forward thrust or square shoulders.

Table 3 The shoulder features of two dissatisfied subjects, and requisite pattern adjustments performed by the experts

\begin{tabular}{|c|l|l|c|}
\hline $\begin{array}{l}\text { Subject } \\
\text { No. }\end{array}$ & \multicolumn{1}{|c|}{ Features of body type } & \multicolumn{1}{|c|}{ Pattern adjustment } & $\begin{array}{c}\text { Satisfaction } \\
\text { score }\end{array}$ \\
\hline 3 & Forward thrust shoulders & Extend $0.5 \mathrm{~cm}$ of shoulder part upward & 8 \\
\hline 6 & Square shoulder & Add the ease $1 \mathrm{~cm}$ around the shoulder line & 9 \\
\hline
\end{tabular}

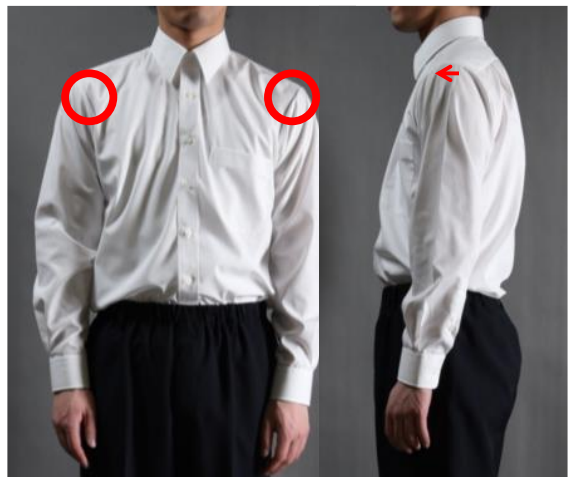

(a) subject 3

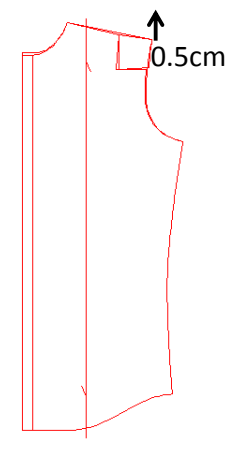

(b)pattern

Figure 5: Pictures of subject 3 and his pattern adjustment 


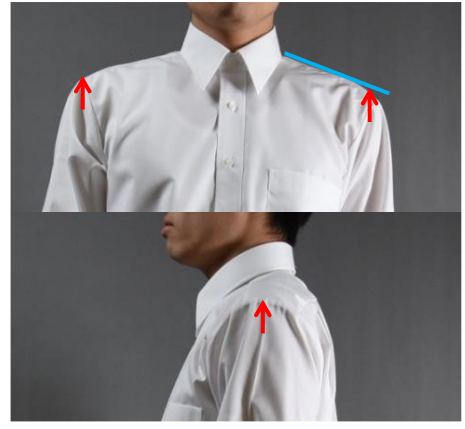

(a) subject 6

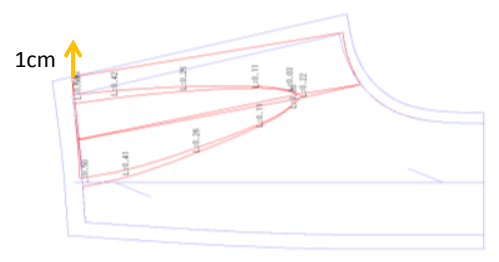

(b)pattern

Figure 6: Pictures of subject 6 and his pattern adjustment

\section{Characterization of shoulder shape}

Through wearing experiments and evaluation by experts, we identified two subjects during our initial evaluation who complained about the shoulder fit of their shirts. One has a square shoulder shape and the other one has a forward thrust shoulder shape. To investigate the characteristics of these shoulder shapes, we compared the three-dimensional shapes of the two subjects to a dummy that represents the average Japanese male body size (MD-20A, NANASAI Co., Ltd, Japan). A three-dimensional scanner (Body Line Scanner, Hamamatsu Photonics, Japan) was used to create a three-dimensional representation of the subjects and the dummy. We compared their silhouettes and cross-sectional shapes. The relationship between the adjustments to the standard shirt used in the wearing test and the three-dimensional characteristics of the subjects' shoulder shapes was also investigated.

Figure 7 shows a comparison of the shoulder angles of subject 3, 6 and the average dummy. Compared with the average dummy (24-degree shoulder angle), subject 3's shoulder angle was 24.5 degrees. The shoulder angle of subject 6 was 20 degrees. Figure 8 compares the shoulder shapes of subjects 3,6 and the average dummy. Compared with the dummy, subject 3's shoulder point is anterior, and subject 6's is superior. Figure 9 compares the armhole position of subject 6 and the dummy. The armhole of subject 6 was located superior to that of the dummy. Figure 10 shows the seam lines of subject 3, the ready-to-wear shirt and the modified shirt. The shoulder seam line of the ready-to-wear shirt was parallel to that of subject 3 . By modifing the shirt pattern, the shoulder seam line was moved closer to the shoulder line. The shoulder point of the shirt was particularly improved.

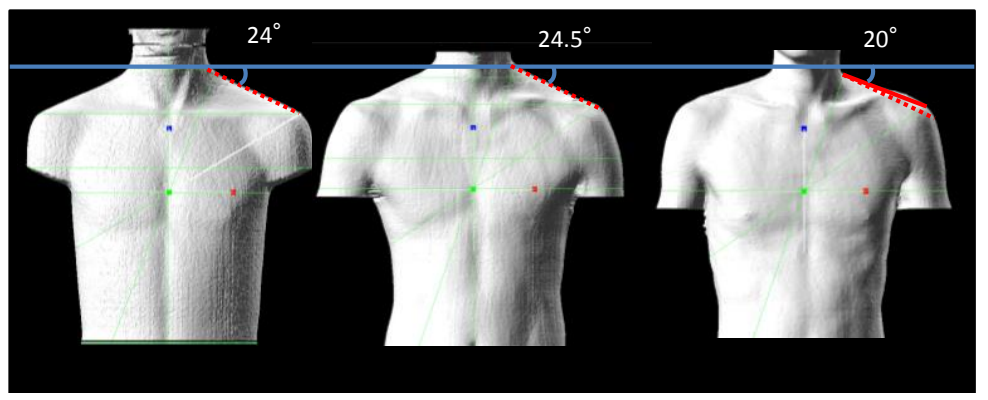

(a) average dummy

(b)subject 3

(c)subject 6

Figure 7: A comparison of the shoulder angles of subject 3, subject 6 and a dummy representing the average Japanese male shoulder (Front) 


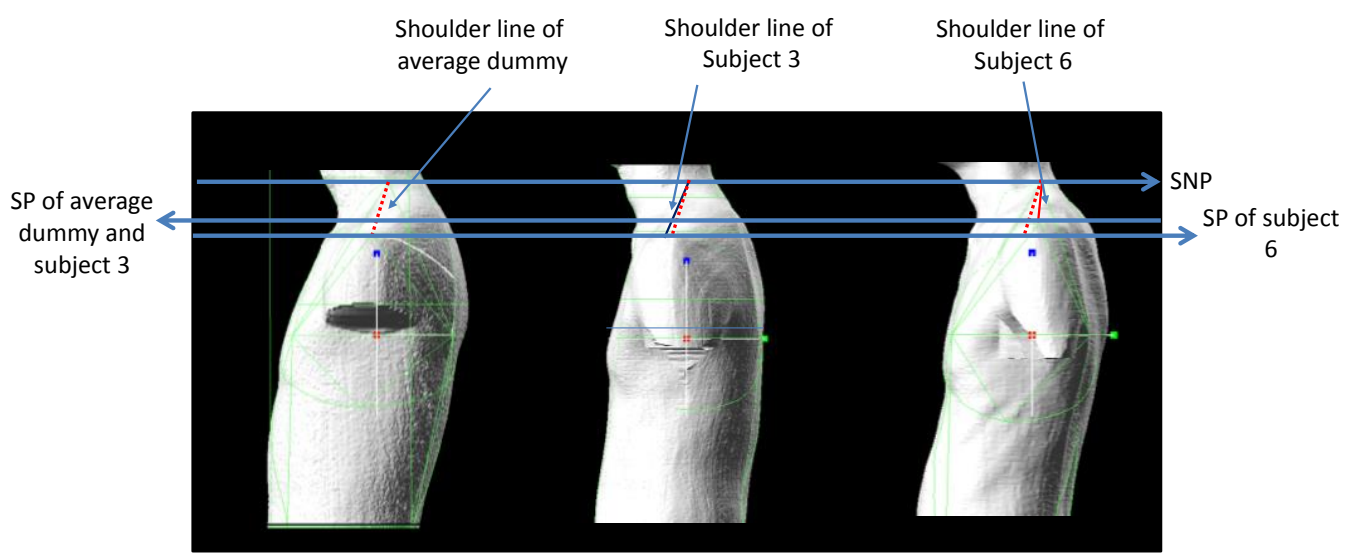

$\begin{array}{lll}\text { (a) average dummy } & \text { (b)subject } 3 & \text { (c)subject } 6\end{array}$

SP: shoulder point, SNP: Side neck point

Figure 8 A comparison of the shoulder shapes of subject 3 , subject 6 and a dummy representing the average Japanese male shoulder (side)

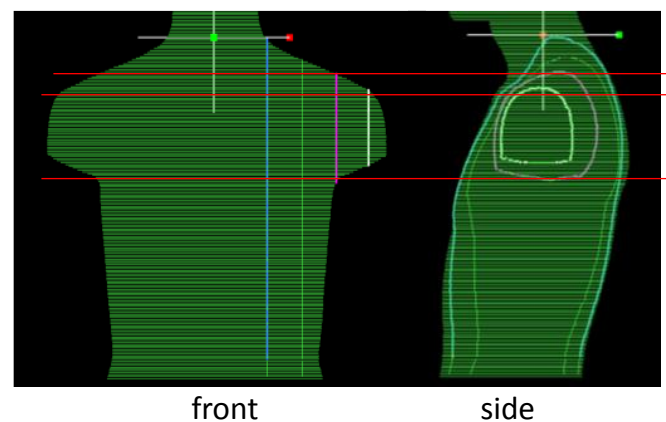

(a) average dummy

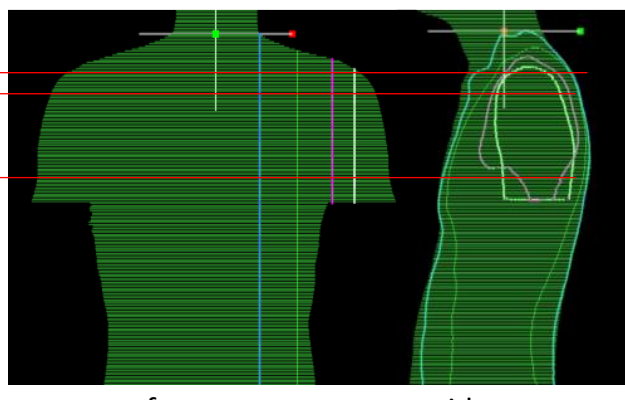

front

(b)subject 6

Figure 9 A comparison of the armholes of subject 6 and a dummy representing the average Japanese male shoulder
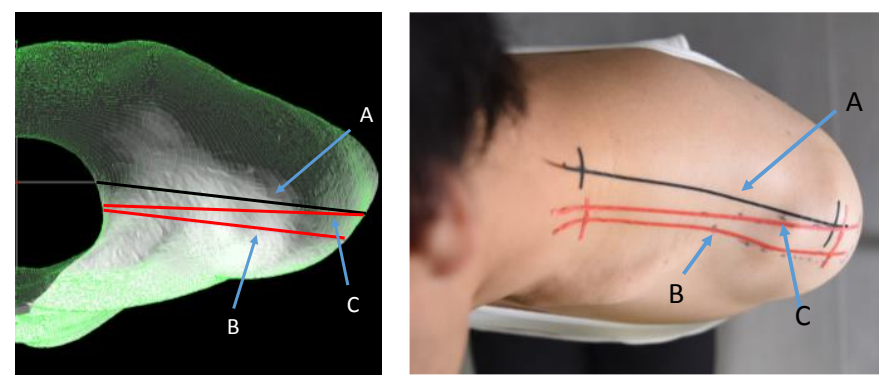

Figure 10 The shoulder line of subject 3 (A),the shoulder seam line of the ready-to-wear shirt (B), and the shoulder seam line of the modified shirt that improved subject 3's overall comfort (C)

\section{New measurement methods of shoulder shape and its verification}

To adjust the design of the ready-to-wear shirt, we found that it is necessary to distinguish the wearers' shoulders shapes. We therefore created a shoulder shape measuring device as shown in Figure 11. The device is made of two transparent acrylic plates with hinges. On the plates, the point of the seventh cervical vertebrae and the shoulder point (SP) of the average dummy were marked. Measurements were performed by applying the template to the subject's shoulders between both of his seventh cervical vertebrae points (BNP). The setting point for the seventh cervical vertebrae point (BNP) of the plate is set on a subject's BNP. The setting point for the side neck point is set on the subject's side point. Then, a shoulder line between side neck point and shoulder point can be marked on the plate. With the positional relationship between the subject's shoulder point and the one marked on the device, the shoulder front or back thrust angles were measured as shown in Figure 12. The anterior-posterior direction of the shoulder line was measured using an angle $\theta$ made up of a line connecting the 
side neck point (SNP) and SP and the coronal plane. In addition, the shoulder slope was measured using angle $\varphi$, composed of the two acrylic plates as shown in Figure 13.

Using the proposed method, we measured the shoulder angle and direction of 24 Japanese male subjects in their 20s, including Subjects 3, 4, 5, 6, 7 and 9. By measuring angles $\theta$ and $\varphi$, we were able to adjust the shirt designs of two subjects and verified our methodology through wear tests comparing the adjusted shirts.
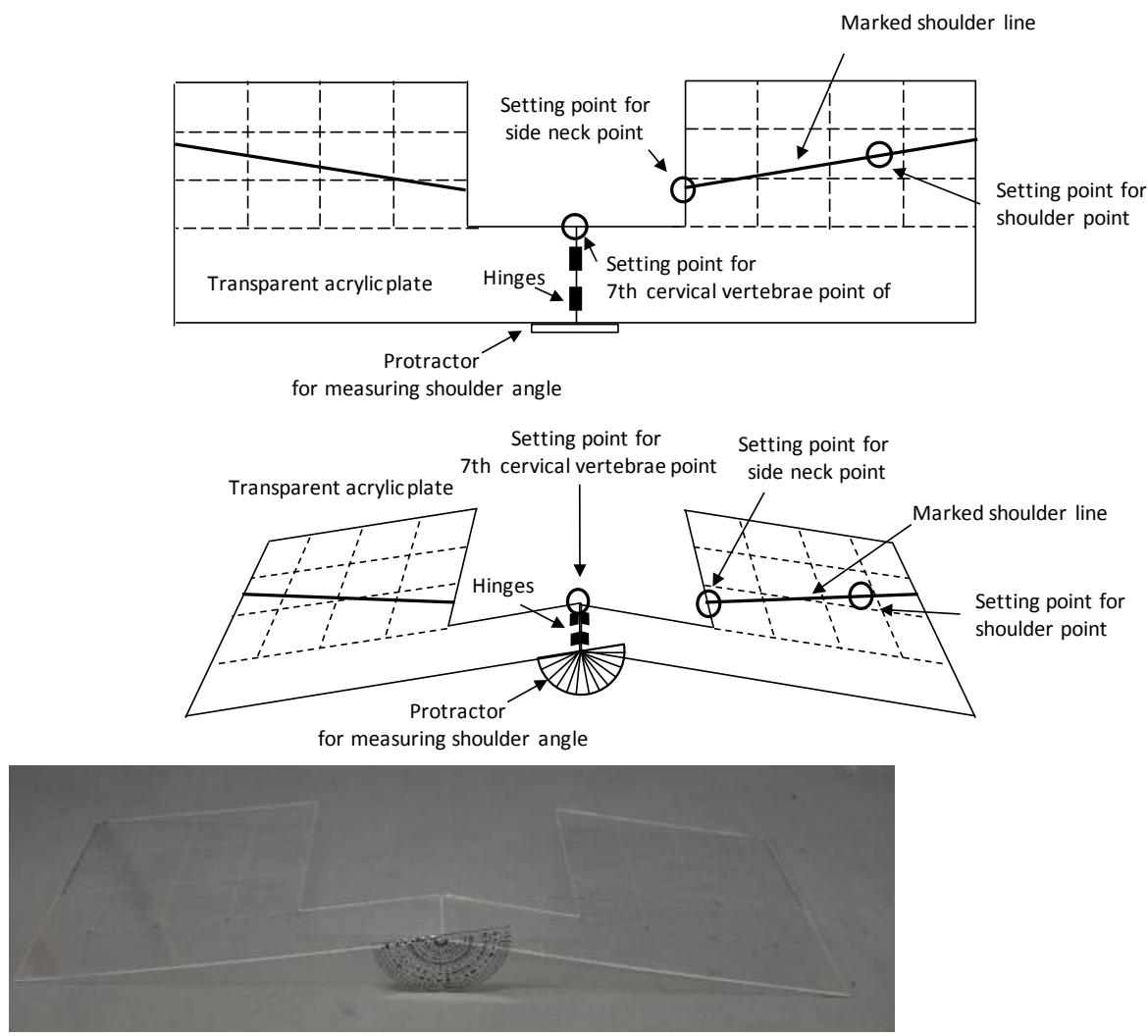

Figure 11 Shoulder shape measuring device

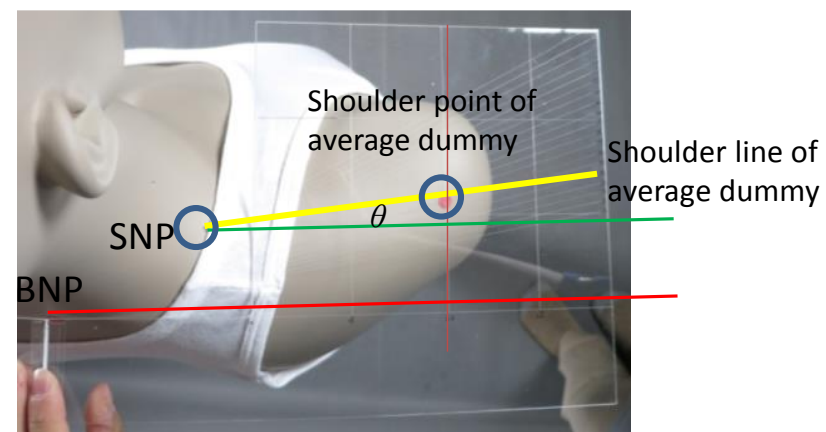

Figure 12 measurement of shoulder point front-back direction

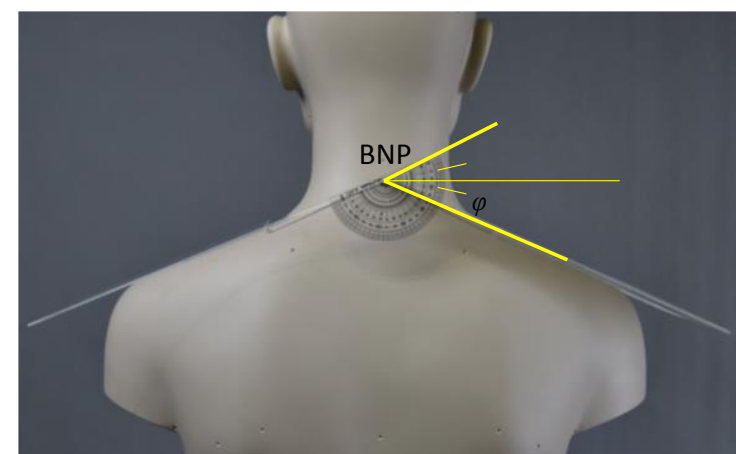

Figure 13 Measurements of the shoulder slope

Figure 14 shows the relationship between the shoulder angle and the shoulder point direction as determined by the shoulder shape measurement. From this data it was found that the dummy representing the average Japanese male has a sloping shoulder with a slight forward thrust. It was also found that subjects 3 and 18 have an increased degree of shoulder sloping and forward thrust compared with the dummy. Subject 6 has a square shoulder with a backwards thrust.

To verify the obtined values, we adjusted the ready to wear shirt of subject 18 ' size with the same method and amount of Subject 3, as shown in Figure 5. When subject 18 wore the ready-to-wear shirt, he commented that the shoulder component was tight. However, he noted that the modified shirt was more comfortable than the ready-to-wear shirt.

A shirt company can make various shirt patterns according to $\theta$ and $\varphi$ based on their master pattern. 
At first, certain range of $\theta$ and $\varphi$ which pattern adjustment is not needed should be obtained by wearing tests. Then, for a customer who require some adjustment, a shirt maker obtain the relation between adjustment amount, as shown in figures 5 and 6 , and the values of $\theta$ and $\varphi$. After those preparation, by measuring customers' $\theta$ and $\varphi$, a shirt maker can propose a fit shirt. This method also can be used for making a custom-made shirt.

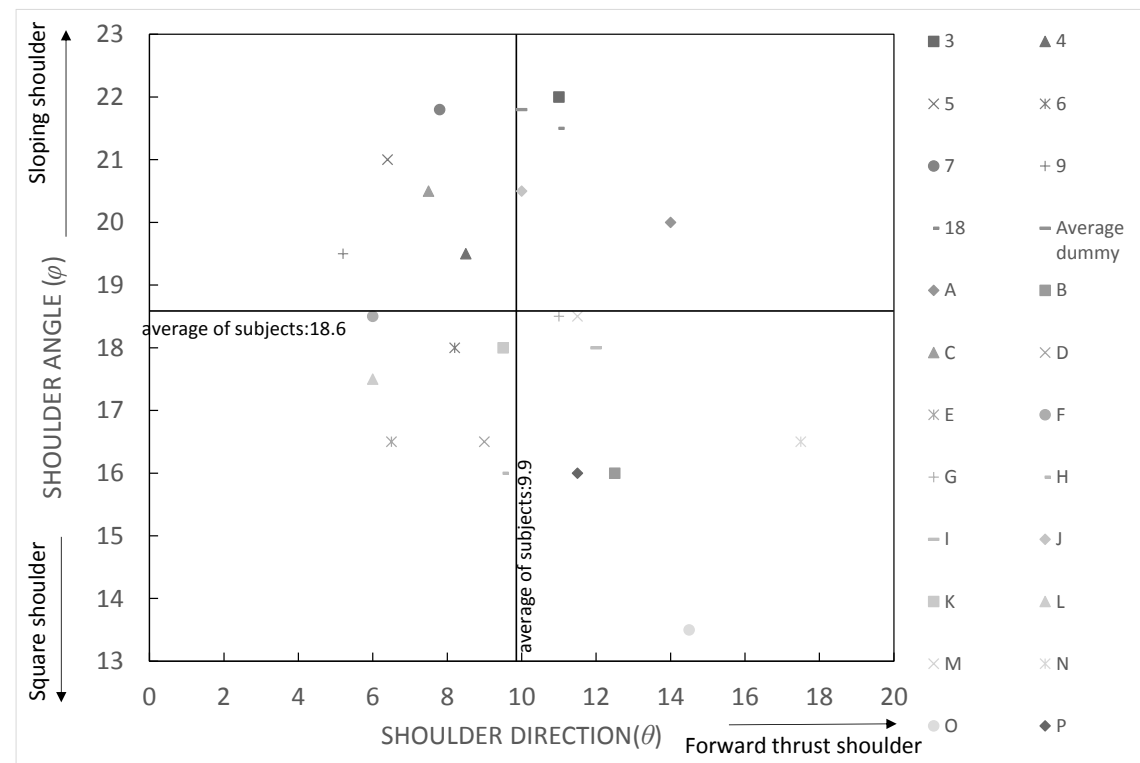

Figure 14 The relationship between the shoulder angle and the shoulder point direction

\section{Conclusion}

By performing a wear test using a ready-to-wear shirt, it is clear that the points of dissatisfaction with ready-towear dress shirts include the tightness of the neck and poor sleeve and shoulder matches. Experts were able to choose a shirt with an appropriate size from the common stock sizes to manage all complaints but those related to shoulder fit, so long as the adjustments were confirmed with a repeat fitting. Shoulders with a forward thrust or square shape were characterized by three-dimensional analysis. In the forward thrust shoulder, the shoulder point and shoulder line were located anterior compared with the average Japanese male. The square shoulder also had a smaller shoulder angle than the average Japanese male. Based on these characteristics, we devised a measuring device to assess the slope, shape and thrust of the shoulder. By measuring the shoulder's direction and angle, it is possible to understand the wearer's shoulder type and what adjustments are necessary. To verify the usefulness of this proposed method, additional wear experiments on various body types will be necessary.

\section{Acknowledgements}

This work was supported by JSPS KAKENHI under grant numbers JP24220012.

\section{Reference}

Coffin, D. P. (1998) Shirt making: Developing skills for fine sewing. Taunton Press, Newtown, CT.

Cooklin, G. (2000) Pattern Grading for men's clothes: the technology of sizing. Blackwell Scientific

Publications, Hoboken, NJ.

Makabe, H. and Beppu, M. (1997) "The construction of the basic system for the clothing pattern design (Part. 1) The indispensable measurement items of the upper body", The Japanese Journal of Ergonomics, Vol. 33 No. 1, pp. 35-46.

Beppu M. and Makabe H. (1998) "The construction of the basic system for the clothing pattern design (Part. 2) The indispensable measurement items of the lower body", The Japanese Journal of Ergonomics, Vol. 34 No. 1, pp. 17-27.

Chan, A. P., Fan, J. and Yu, W. (2003) "Men's Shirt Pattern Design: Part I: An Experimental Evaluation of Shirt Pattern Drafting Methods", Sen-I Gakkaishi, Vol. 59 No. 8, pp. 319-327.

Chan, A. P., Fan, J. and Yu, W. (2003) "Men's Shirt Pattern Design: Part II: Prediction of Pattern Parameters from 3D Body Measurements", Sen-I Gakkaishi, Vol. 59 No. 8, pp. 328-333.

Chan, A. P., Fan, J. and Yu W. M. (2005) "Prediction of men's shirt pattern based on 3D body measurements.", 
International Journal of Clothing Science and Technology, Vol. 17 No. 2, pp. 100-108.

Chen, C-M. (2007) "Fit evaluation within the made-to-measure process", International Journal of Clothing Science and Technology, Vol. 19 No. 2, pp. 131-144.

Ives, B. and Gabriele P. (2003) "Custom made apparel and individualized service at Lands' End", Communications of the Association for Information Systems, Vol. 11 No. 1, p. 3.

Japanese Standards Association, Japanese Industrial Standards hand book, JIS L 4107, Sen-I (2015) 